\title{
A systematic evaluation of game elements effects on students' motivation
}

\author{
Rui Leitão ${ }^{1,2} \mathbb{D} \cdot$ Martin Maguire $^{1} \cdot$ Sarah Turner $^{3} \cdot$ Laura Guimarães $^{2}$
}

Received: 27 January 2021 / Accepted: 24 June 2021 / Published online: 7 July 2021

(c) The Author(s) 2021

\begin{abstract}
Motivation theory is indispensable when discussing processes of learning. Learners who are motivated can learn almost everything. Students' motivation is probably one of the most important factors for teacher effectiveness both for engagement in the learning process and high academic performance. To have effective environmental education, it is not only necessary to inform the public about the ocean but also to involve and engage them is essential. Motivation and engagement are some of the most commonly mentioned concepts in gamification, thus, a gamified application seems to have the necessary features to improve the motivation of students in the learning context of Ocean Literacy topics. The main aims of this work were: i) to understand through a systematic evaluation, how game elements affect the different motivation layers; and ii) to compare them in terms of enhancing the motivation to recycle among secondary school students (11-14 years). To measure students' motivation, a pre-test and a post-test using a recycling situational motivation survey were administered in a classroom environment in Portugal and the UK. Findings show a trend regarding the effect of game elements mainly on the most autonomous forms of motivation. The different game elements, each one with different degrees of effects, were shown to have potential to increase motivation.
\end{abstract}

Keywords Educational tools · Motivation · Engagement - Gamification · Mobile applications $\cdot$ Ocean literacy

\section{Introduction}

Commonly, gamification is employed as an approach which involves selecting elements of games to create a game-like environment in order to improve the user experience and increase the user's motivation and engagement (Dichev \& Dicheva, 2017; Hense \& Mandl, 2014; Przybylski et al., 2010; Sailer et al., 2017; Werbach,

Rui Leitão

r.leitao@lboro.ac.uk

Extended author information available on the last page of the article 
2014). Motivation means to be moved to do something, to perform an action, and in the educational field it is considered one of the most essential factors for teaching and learning effectiveness (Çakıroğlu et al., 2017; Dichev \& Dicheva, 2017; Lawlor et al., 2016; Williams \& Williams, 2011).

Gamified applications are commonly related to a cognitive process of intrinsic motivation where users perform an activity without any kind of conditioning, just for fun, as a culmination of an autotelic activity - one that is internally driven (Leitão et al., 2019c; Liu et al., 2017; Przybylski et al., 2010; Rigby, 2015; Ryan et al., 2006). Besides, previous research indicates that the design process should rely less on extrinsic motivator stimuli, as their effects not only diminish over time (Thiebes et al., 2014) but may also undermine intrinsic motivation (Hamari et al., 2014).

Associated to gamification, the literature shows several studies on motivation among which the self-determination theory (SDT) is the most popular approach (Deterding, 2015; Loughrey \& O Broin, 2018; Seaborn \& Fels, 2015). SDT is a broad framework for the study of human motivation that defines intrinsic and varied extrinsic layers of motivation (external regulation, introjected regulation, identified regulation and integrated regulation) (Deci \& Ryan, 1985). Despite the growing popularity in the education field, "the theoretical underpinnings of gamification remain poorly understood, which has led to numerous failures and criticisms of the process" (Loughrey \& O Broin, 2018). According to several authors (Dicheva et al., 2019; Loughrey \& O Broin, 2018; Rapp et al., 2019; Thiebes et al., 2014), evidence on the motivation effects of gamification remains scarce, and there is limited empirical evidence on motivational influences driving students to participate in gamified activities.

\section{Environmental education}

The protection of the Ocean has become one of the most urgent points in the world environmental agenda (Pantò, 2019). Despite the unquestionable importance of the ocean to the environment and Earth's sustainability, research has shown low levels of understanding of ocean-related topics among the citizens from several different countries (Ankamah-Yeboah et al., 2020; Costa \& Caldeira, 2018; Guest et al., 2015; Papathanassiou et al., 2017; Tran, 2009; Winks et al., 2020). Most of the people are not aware of the impact of the ocean on their lives (Frick et al., 2004; Pantò, 2019) and there is little understanding of marine environmental issues and protection (Fauville et al., 2019). The lack of these scientific concepts, prevents people from making conscious personal and societal decisions about ocean issues (Goodale, 2020; Marrero \& Mensah, 2010).

The Ocean Literacy concept was developed to increase the understanding of people's influence on the ocean and vice versa (Cava et al., 2005). Thus, the literature involving the evaluation of ocean literacy has focused not only on content knowledge but also on environmental attitudes and dispositions (Goodale, 2020). A common denominator of all the issues that has a detrimental effect on the ocean and on climate change is the waste we produce. Falasca-Zamponi starts from the provocative observation that the debate around climate change stands as a defence of 
consumption, and the waste is its consequence (Falasca-Zamponi, 2010). Accordingly to the European Environment Agency, evidence shows that human-induced change in marine ecosystems has greatly increased in the past 60 years, and some of the main threats are water pollution and eutrophication (EEA, 2019).

Mercer et al. (2017) stress that in order to "deliver effective education for sustainable development, suitable pedagogies are needed and this is seen as requiring a shift away from more traditional learning and teaching approaches". For this to be possible, interactive and discursive teaching methods are needed. Daigle (2003) has argued for the need for greater public involvement saying that "the only hope for further progress on environmental protection and sustainable development lies with a public that is not only informed but also engaged" (Daigle, 2003, p. 230).

\section{Research tool - matching motivation to game elements}

Academic research on gamification, in the motivation evaluation, has commonly studied multiple game elements in combination, and not individually. This makes it impossible to establish whether individual elements have different effects or not (Denny et al., 2018; Hamari et al., 2014; Landers et al., 2017; Mekler et al., 2013); and when they are used alone, studies merely add different elements to existing systems or products as a one-size-fits-all solution (Chou, 2016; Kornevs et al., 2019; Liu et al., 2017).

For the same game element, it is possible to reach quite different conclusions. For example, Nevin et al. (2014) concluded that leaderboards were the most important motivator for participants, while Ibáñez and Delgado-kloos (2014) stated that leaderboards were not reported as appealing. Çakıroğlu et al. (2017) reported that in practical activities, competition came to the forefront as a negative element, whereas Nevin et al. (2014), in a different perspective, stated that the ability to compete both individually and in teams appealed to a great number of users. The reasons for these differences need to be better understood and therefore, studies on motivation regarding the use of single game elements should be further conducted. The perspective of merely adding different game elements to an application without understanding the meaning behind them has been raising some criticism (Chou, 2016; Esteves, 2017; Kornevs et al., 2019; Liu et al., 2017; Park et al., 2019; Werbach \& Hunter, 2012). Likewise, Chee and Wong (2017) noted that most gamified systems neglect the essence of games and what makes them powerful, such as the behavioural and psychological processes that underlie them. "The mere inclusion of meaningless points, badges, and bright colours, which serve as the catalysts to engagement without full comprehension of their purpose or reason of attainment, fails to make a gaming experience fun and engaging" (Chee \& Wong, 2017). Furthermore, people do not play a game because of the game elements, but because they "contain elements of story, challenge and continual feedback as well as a high level of interactivity" (Kapp, 2012).

The flow theory by Mihaly Csikszentmihalyi (1999) is widely accepted to be one of the fundamental models to improve the game experience (Xu, 2011). The author describes the concept as a process of optimal experience "that is so engrossing and 
enjoyable that it becomes autotelic" (Csikszentmihalyi, 1999). On a broader viewpoint, flow theory seems very similar to the intrinsic motivation layer of the selfdetermination theory by Deci et al. (1999). Csikszentmihalyi (2000) defined fun as a positive emotional state of playful enjoyment and a component to a person engaging the flow state. Furthermore, an intrinsically motivated person, values the experience by itself, rather than the experience as an instrument to achieve something else (Deci et al., 1999). Since motivation is considered one of the most important factors for teaching and learning effectiveness (Çakıroğlu et al., 2017; Dichev \& Dicheva, 2017; Lawlor et al., 2016; Williams \& Williams, 2011), applying the flow theory in application experience development can help to foster a more engaging and, consequently, a more effective gamified learning experience.

The Ocean Literacy application employed in this investigation consisted of a game mechanic where the user had to throw a sequence of items into the right bin. This game mechanic was previously tested with students, where they participated and contributed in different roles to the design process in order to understand their real needs (Leitão et al., 2019b). Whenever the user fails in throwing an item into a bin, or an item is introduced in a wrong bin, they lose one life. The life loss in this application is represented by a dirtier water level. Therefore, each time the player fails to recycle, the water becomes darker, the fish start to die on the water's surface, and the game ends (see Fig. 1).

Based on the Flow theory, for the optimal experience to happen a balance between challenges and skills is necessary (Csikszentmihalyi, 2014). This balance was sought, e.g. through the relationship between the different types of waste appearing in the game, the time to throw them into the correct bin, and the necessary speed to act. All these elements were grouped into three types of waves or game stages (see

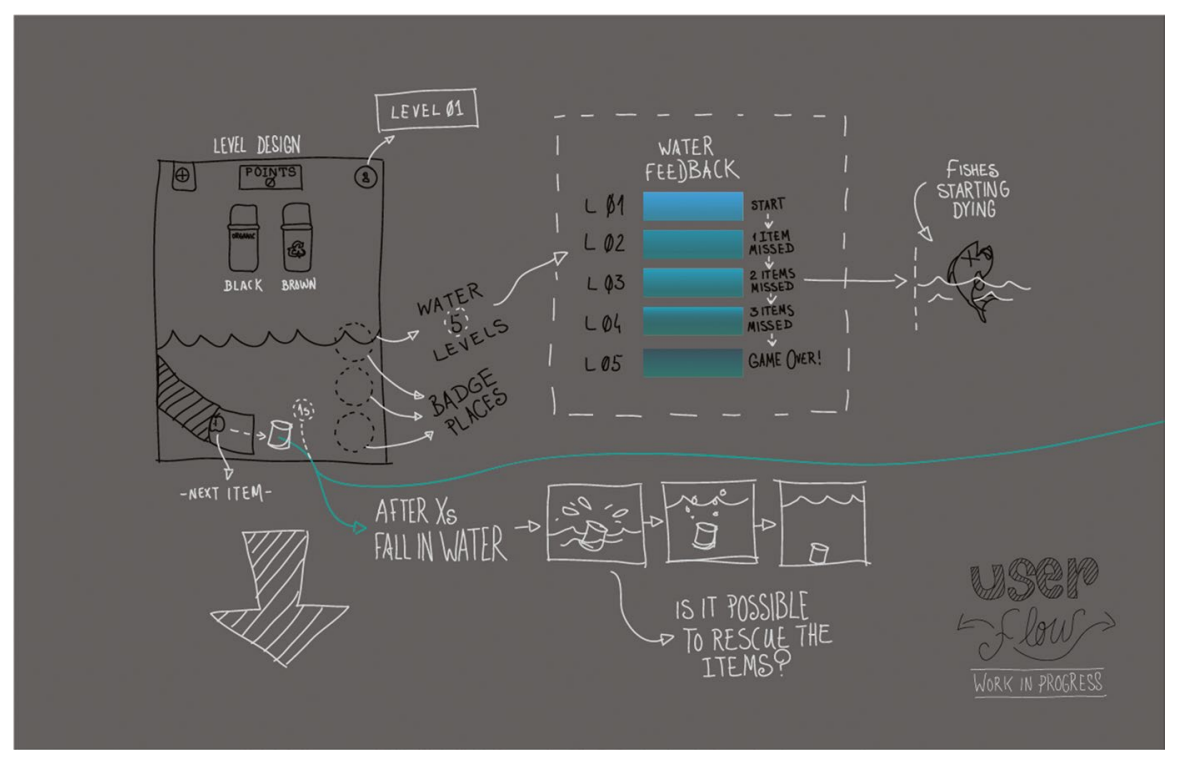

Fig. 1 Visual feedback mock up. Water levels associated with losing game lives scheme 
Fig. 2). Clear goals were added in the form of tutorials before each level started, through a clear graphical user interface meant to show users how to accomplish the tasks. The user received immediate feedback of all the actions performed in a visual form through buttons, menus and other navigation items, and also through sounds. The immediate feedback to the user's actions also relates their actions with effects on water. As users increase their skill level, they become bored unless the application increases the challenge to match the increased abilities. Therefore, another balance between challenge and user skills was sought regarding the opportunities for recycling while they progressed through the different levels.

The gamification concept in this study is connected to making learning experiences more engaging by using game design elements and game design techniques. The present study intended to understand how interacting with a mobile gamified application about ocean literacy topics in learning activities can raise awareness of the impact that our daily choices have on the marine ecosystem. Since previous gamified studies have yielded contradictory findings and one sharp criticism is that multiple game elements were often studied in combination, (Denny et al., 2018; Hamari et al., 2014; Landers et al., 2017; Mekler et al., 2013), the research prototype Ocean Literacy was developed to help answer this concern. The selection of these game elements lied on the literature, which reported that the PBL triad (points, badges and leaderboards) is one of the most commonly used gamification elements (Dicheva et al., 2018; Kirillov et al., 2018; Werbach \& Hunter, 2012; Zichermann \& Cunningham, 2011). One of the reasons for the widespread use of these elements is the idea of easy implementation compared to other ones (Chou, 2016; Dicheva et al., 2018). Thus, to better understand their effects, four different

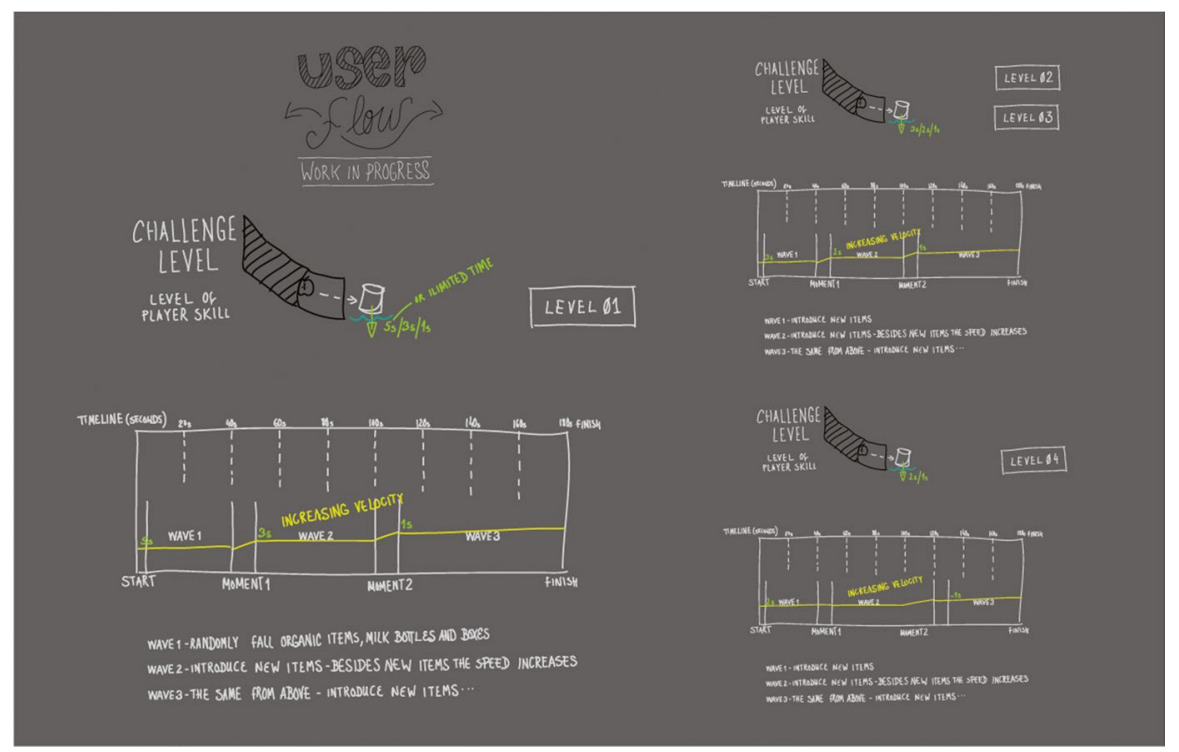

Fig. 2 Timeline, speed, novelty and waves. Skills level flow mock up related with the drop of waste throughout the levels 
versions of Ocean Literacy were developed and implemented as an application on iOS and Android-based mobile devices, and their effectiveness regarding students' motivation was compared. The four versions were exactly the same except for the game element employed. The final application is available at Google Play and Apple Store (Leitão et al., 2019a). This study started from the research question: can different game elements affect students' motivation to recycle and, if so, how? Moreover, it explores the use of the game elements points, badges, leaderboard individually, and the PBL triad, to understand which of these affects the situational motivation to act and recycle. The study specific objectives were: (a) understand which of the game elements affects the different motivation layers; (b) compare the game elements for enhancing the motivation to recycle; (c) evaluate which game elements are better at motivating and engaging learners.

\section{Method}

Self-determination theory (SDT) is an essential theoretical perspective to understand individuals' motivation, and it was adopted in this study since it is widely accepted in different fields (Liu et al., 2017; Standage et al., 2003). Based on this theory, the Situational Motivation Scale (SIMS) (Guay et al., 2000) measures students' situational motivation when they are engaging in an activity. The SIMS was used since it is a well-validated situational measure of motivation (Guay et al., 2000; Lonsdale et al., 2011; Østerlie et al., 2019; Standage et al., 2003). The recycling situational motivation (RecycleSIMS) survey used to collect data from the students in this study was adapted from SIMS (Guay et al., 2000). The adjustment consisted of changing the intention of the activity, e.g. SIMS item "I am doing this activity for my own good" was changed for "I recycle for my own good". Students were asked to rate different reasons for recycling, on a Likert scale ranging from disagree strongly (1), to agree strongly (5). The survey included four items for intrinsic motivation (1-Because I think that recycling is interesting, 5-Because I think that recycling is pleasant, 9-Because recycling is fun, and 13-Because I feel good when I'm recycling); four items for identified regulation (2-Because I recycle for my own good, 6-Because I think that recycling is good for me, 10-Because it is my personal decision to do it, 14-Because I believe that recycling is important for me); four items for external regulation (3-Because I am supposed to do it, 7-Because it is something that I have to do, 11-Because I don't have any choice, 15-Because I feel that I have to do it); and four items for amotivation (4-There may be good reasons to recycle, but personally, I don't see any, 8-I will recycle, but I am not sure if it is worth it, 12-I don't know, I don't see what recycle brings me, 16-I recycle, but I am not sure it is a good thing to pursue it).

The sample of this study consisted of school children in Portugal and the UK within the age group 11-14 years, corresponding respectively to 7 th to 9 th grades and KS3. Data were collected in July 2019 and a total of 98 students responded to the motivation survey $(\mathrm{PT}=69, \mathrm{UK}=29)$ in classroom sessions. The students were randomly organised in five different groups/sessions per country. The class sessions where the survey were administered consisted of the learning activity 
related to ocean topics (oral explanations with a slideshow presentation of some key topics related to ocean health), and afterwards, the students interacted with the ocean literacy application (Fig. 3). The data were collected anonymously in both Portugal and the UK, through administration in each session of the survey in paper format using a Pre-test and Post-test Design, i.e. before and after the learning activity, as described in Table 1 . Four sessions were set to test the game elements and a session only with oral explanations was the control group.

All students had the opportunity to fill in the survey without being observed, and to ask questions if anything was unclear. To minimise any pressure, they were asked to answer as truthfully as they could, along with an assurance that there were no wrong or right answers. To comply with research ethics requirements, a request for ethical approval was submitted in both countries before the study started. Permission was obtained from students, parents, teachers, and headteachers.

The collected data were analysed by paired-samples t-tests using IBM SPSS version 24. The dependent t-test compares the means between two related groups on the same continuous, dependent variable. This analysis was used to understand whether there was a difference in children's motivation before and after they interacted with the application using different game elements and also following a traditional class environment experience.

\section{Results}

The school children involved with all the ocean literacy versions of the application found them accessible with variable degrees of effectiveness as motivation tools. Although the different states of motivation analyses in the UK and in Portugal are not statistically significant, the results show a similar trend concerning the effect on students' motivation to recycle in the two countries.

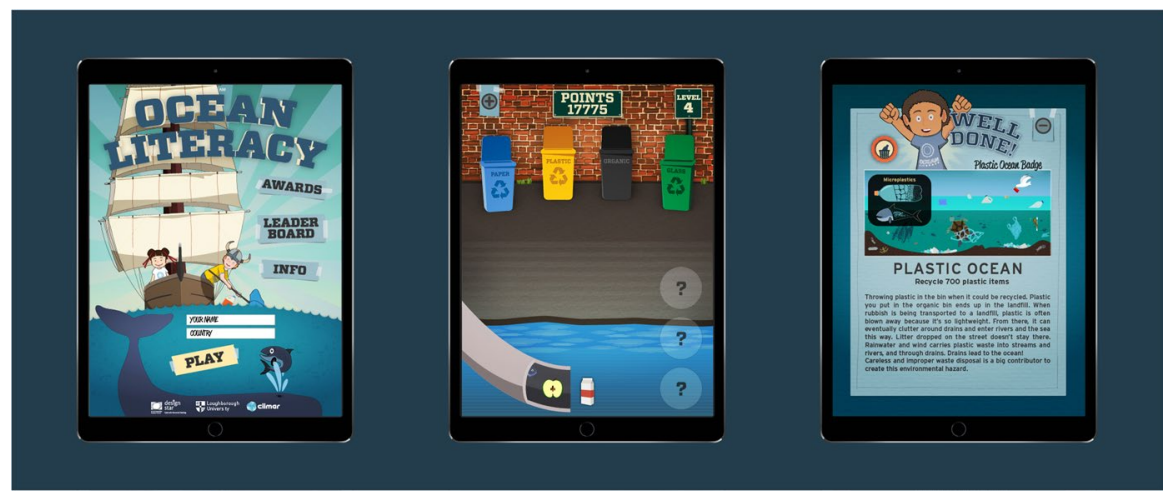

Fig. 3 The Ocean Literacy application ( Leitão et al., 2019a) 


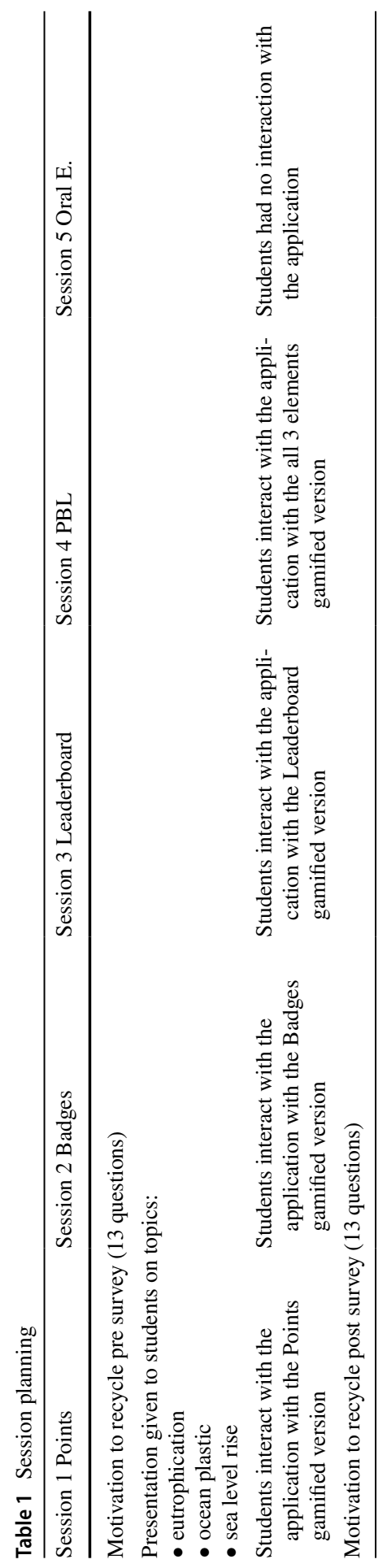




\subsection{Findings for the students in the UK}

Table 2 presents the means for the RecycleSIMS scale estimated at both assessments (before and after). The results regarding the game element points show a positive effect on the different motivation layers except for external regulation, which decreased. Intrinsic motivation scores increased by $6.3 \%$, identified regulation increased by over $1 \%$, and external regulation showed the highest effect of all the five-session conditions, decreasing $11 \%$. Amotivation not only decreased but also registered the highest effect of the element points $(-15 \%)$; therefore, the overall results show a positive effect of this element on the students' motivation to recycle.

The results regarding the element badges also show an increase in intrinsic motivation among UK students (3.5\%). This game element did not appear to have an effect on identified regulation, while external regulation decreased by $4.5 \%$. This session presented a high positive impact on students' amotivation, which decreased by $25 \%$. Regarding the leaderboard element, results improved in all the three sets of motivation processes: intrinsic, extrinsic and amotivational. Intrinsic motivation increased by $25.6 \%$, identified regulation around $11 \%$, and external regulation showed the highest results among all the sessions, increasing over $20 \%$. The element leaderboard showed a negative effect on amotivation, which also increased around $13 \%$.

When students interacted with the full application, which included the PBL triad, the findings displayed the best impact over all the sessions. Intrinsic motivation and identified regulation both showed the highest results among all the sessions, increasing by $28 \%$ and $26 \%$ respectively. External regulation increased by $15 \%$ and amotivation decreased by $7.5 \%$. On the other hand, the oral explanation session showed the lowest effect on all the motivation continuum, except on identified regulation which increased by $9.72 \%$. The oral explanation session did not have an effect over intrinsic motivation and external regulation, and regarding amotivation, it obtained the highest increase of all the conditions (over 16\%).

Intrinsic motivation is commonly known as the most productive force behind people's behaviour. Overall results indicate that the game element leaderboard and

Table 2 Overall paired samples statistics obtained with the recycleSIMS survey (UK students). PBL: points, badges and leaderboard; Pre: Pre-test; Post: post-test; Oral E.: oral explanation

\begin{tabular}{lllllll}
\hline UK $N=29$ & & $\begin{array}{l}\text { Points Mean } \\
N=6\end{array}$ & $\begin{array}{l}\text { Badges Mean } \\
\mathrm{N}=6\end{array}$ & $\begin{array}{l}\text { Leaderboard } \\
\mathrm{N}=6\end{array}$ & $\begin{array}{l}\text { PBL } \\
\mathrm{N}=6\end{array}$ & $\begin{array}{l}\text { Oral E. } \\
N=5\end{array}$ \\
\hline Intrinsic & Pre & 13.00 & 14.17 & 13.67 & 13.00 & 13.60 \\
motivation & Post & 13.83 & 14.67 & 17.17 & 16.67 & 13.60 \\
Identified & Pre & 14.00 & 17.00 & 15.17 & 14.00 & 14.40 \\
regulation & Post & 14.17 & 17.00 & 16.83 & 17.67 & 15.80 \\
External & Pre & 11.67 & 14.83 & 9.67 & 12.33 & 12.00 \\
regulation & Post & 10.33 & 14.17 & 11.67 & 14.17 & 12.00 \\
Amotivation & Pre & 11.17 & 7.83 & 10.00 & 8.83 & 8.60 \\
& Post & 9.50 & 5.83 & 11.33 & 8.17 & 10.00 \\
\hline
\end{tabular}


the PBL triad had the highest effect on this layer of motivation. Findings show that intrinsic motivation increased in all the conditions except when the students did not interact with the application.

Extrinsic motivation refers to participation in an activity because of external factors rather than due to the activity itself. All the sessions had a positive effect on the students identified motivation except when they experienced the application with the game element badges. In this latter case, the results did not show any variation. Although external regulation decreased with the game elements points and badges, this increased when the students interacted with the application with the game element badge and with the PBL triad. Students' external regulation did not present any changes regarding the oral explanation session.

Amotivation scores decreased throughout all the sessions except in the case of the leaderboard element and when the students experienced a traditional class environment. These overall results among the UK students seem to show that the Ocean Literacy application has had a more substantial positive effect on the students' intrinsic motivation to recycle.

\subsection{Findings for the students in Portugal}

Concerning the Portuguese students, RecycleSIMS scores showed some similarities with the UK sample (see Table 3). Results for the 1st session, showed a positive effect of the game element points on the different types of motivation continuum as well as on amotivation, which decreased by $12,5 \%$. The highest positive effect (4\%) was observed on identified regulation.

Students' intrinsic motivation and identified regulation increased after the experience of the application with the game element badges $(9,4 \%$ and $1,7 \%$, respectively). The effect on external regulation was negative, as it decreased by $11 \%$. On the other hand, badges element presented the greatest effect on amotivation among all the sessions, with a decrease of $18,5 \%$.

Regarding the interaction with the leaderboard game element, overall results showed this to have a positive effect on the students' motivation. The scores for all

Table 3 Overall paired samples statistics obtained with the RecycleSIMS survey (PT students). Legend as in Table 2

\begin{tabular}{lllllll}
\hline PT $N=69$ & & Points Mean & Badges Mean & $\begin{array}{l}\text { Leader- } \\
\text { board Mean }\end{array}$ & PBL Mean & Oral E. Mean \\
\hline Intrinsic & Pre & 14.07 & 16.62 & 13.71 & 15.21 & 16.86 \\
motivation & Post & 14.29 & 17.31 & 15.00 & 17.43 & 15.86 \\
Identified & Pre & 17.50 & 18.23 & 16.71 & 18.36 & 18.14 \\
regulation & Post & 18.21 & 18.92 & 17.00 & 18.43 & 17.93 \\
External & Pre & 13.64 & 12.46 & 11.36 & 14.29 & 10.93 \\
regulation & Post & 14.14 & 11.08 & 11.93 & 14.64 & 10.64 \\
Amotivation & Pre & 5.71 & 5.00 & 5.79 & 6.21 & 4.36 \\
& Post & 5.00 & 4.08 & 6.07 & 5.57 & 4.50 \\
\hline
\end{tabular}


the motivation layers increased ( $\mathrm{IM}=9,5 \%, \mathrm{IR}=1,8 \%$ and $\mathrm{ER}=5 \%$ ). Similar to the UK sample, the students' amotivation levels after interacting with the application also increased (4.8\%). The PBL triad results also showed a positive effect on all the motivation layers, similar to the previous game element. In this session, intrinsic motivation scores increased by around $15 \%$, the PBL triad having the greatest effect of all the sessions on this kind of motivation, as was also the case with the UK students. Identified regulation increased by $0,4 \%$ and external regulation by $2.5 \%$. Students' amotivation decreased by $10 \%$. Similar to the UK students, the control session was shown to harm intrinsic motivation, which decreased by around $6 \%$. Identified regulation and external regulation also decreased by $1 \%$ and $3 \%$, respectively. Moreover, amotivation results also increased by over $3 \%$.

In summary, intrinsic motivation scores indicate that the game element leaderboard and the PBL triad had the greatest positive effect on this layer of motivation. Furthermore, overall results among Portuguese students indicate that intrinsic motivation and identified regulation increased in all the conditions, except when the students did not interact with the application. In the last session, all the motivations layers decreased, and amotivation among them increased. External regulation decreased in two sessions: badges and oral explanation, with a higher effect in the first one. Finally, amotivation decreased with the game elements points, badges and PBL triad, and increased when the leaderboard was the main game element employed in the application.

\subsection{Comparison}

The session results obtained in both samples revealed an overall balance between the UK and the Portuguese experiences. Although the samples sizes were not large, it can be argued that there is a trend related to autonomy or self-determination theory, which is similar in both countries, showing that the application had a positive effect mainly on intrinsic motivation and on identified regulation (Figs. 4 and 5). Globally, the PBL triad appeared as the most effective in improving the motivation layers, especially among the UK students, with highest effects found on intrinsic motivation. The leaderboard was the second best game element in performance, well above the effects elicited by points and badges.

The game elements points and badges were only more effective than the $P B L$ triad and the leaderboard to increase the identified regulation among the Portuguese students (Fig. 4). Identified regulation refers to participating in an activity because its outcomes are valued. Thus, the UK students valued more the ocean literacy topics related to eutrophication, sea-level rise and plastic ocean while interacting with the game elements leaderboard and PBL triad, while Portuguese students valued more the topics while using points and badges as game elements. However, the Portuguese students already started with very high identified regulation values, compared to the UK students (Tables 2 and 3). These findings support a previous study (Leitão et al., 2018), where significantly higher importance and more responsibility was attributed to the ocean by the Portuguese students compared to the UK students. Furthermore, identified regulation overall results suggest that in both countries a 
CHANGES IN INTRISIC MOTIVATION

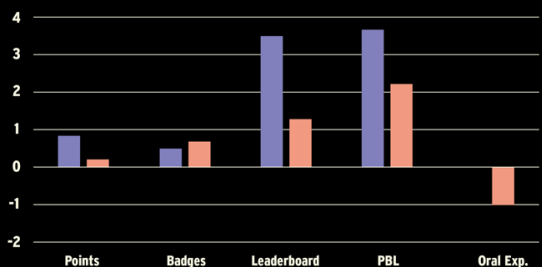

CHANGES IN EXTERNAL REGULATION

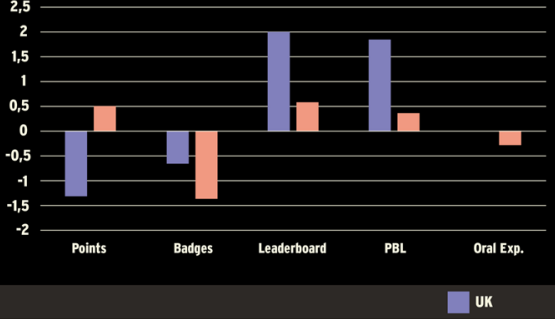

CHANGES IN IDENTIFIED REGULATION

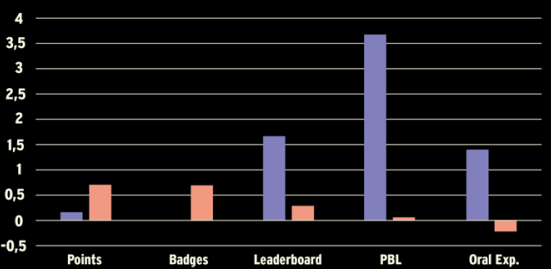

CHANGES IN AMOTIVATION

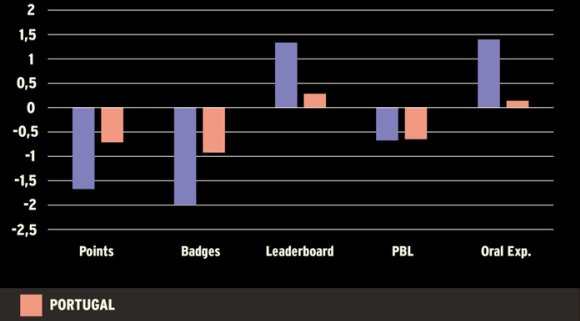

Fig. 4 Changes in intrinsic motivation, identified regulation, external regulation and amotivation elicited by the different game elements (points, badges, leaderboard) or their combination (PBL triad)

\section{OVERALL EFFECTS OF DIFFERENT GAME ELEMENTS ON MOTIVATION}

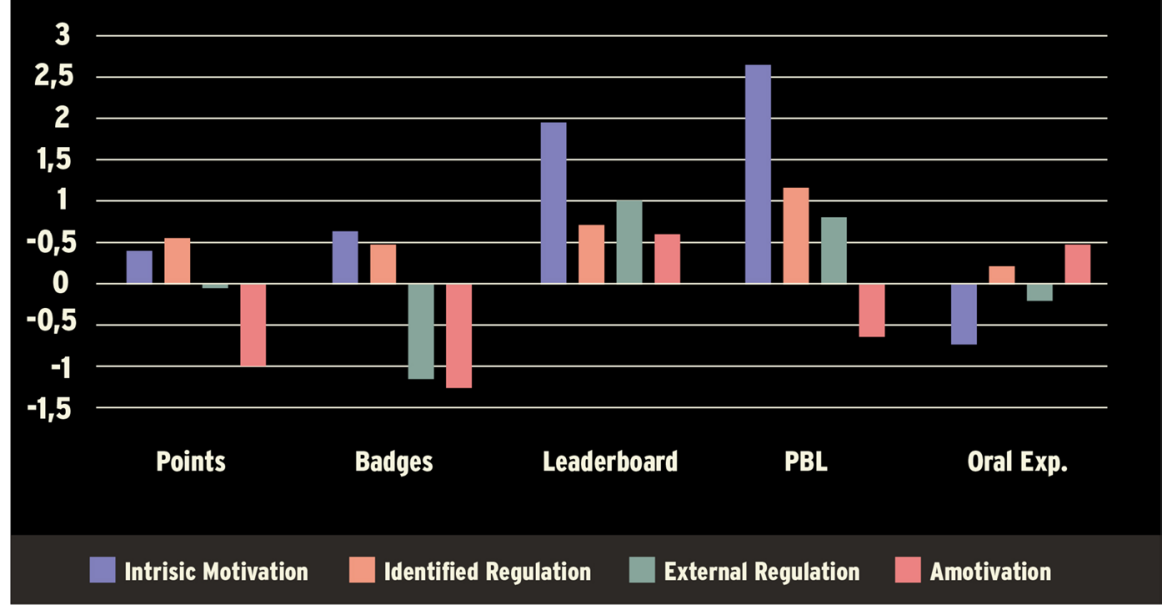

Fig. 5 Overall effects of different game elements on motivation layers 
high percentage of students consider these ocean topics personally important, reinforcing the previous findings (Leitão et al., 2018). The game element leaderboard and the PBL triad increased all levels of motivation in both samples, except in the amotivation level. Opposite to PBL triad, the use of the leaderboard also increased the amotivation (see Fig. 4). The obtained results may be due to the different relationships between leaderboard and students. The immediate feedback provided by this game element and the possibility to improve their place, can be very motivating for competitive students while less competitive students can demotivate and decrease their performance. Finally, the oral explanation (control) session had little or no effect on the motivation layers among the UK students and even decreased motivation among the Portuguese students. The most negative effect of the control session was registered for intrinsic motivation (Fig. 4).

\section{Discussion}

Education is key for future generations and our planet, and teachers want students to learn for learning's sake and not because of the promise of a reward. Consequently, this is one of the main reasons why intrinsic motivation, as opposed to extrinsic motivation, is so important in the education field (Brophy, 2013; Deci et al., 2001). External stimuli can take many forms: contests, prizes, or even grades are a form of external motivation. Although they represent a very effective way of motivating behaviours in a short time period (Ryan \& Deci, 2000a), their effects tend to decrease over time (Magni et al., 2010) and if is perceived to be controlling, can even reduce students' motivation (Deci et al., 1999). This study intended to understand how differently game elements can affect students' motivation to recycle through interacting with a mobile gamified application about ocean literacy-related topics in learning activities. Therefore, it investigated how students' motivation changed following the exposure to the game elements points, badges, leaderboard, and the PBL triad, and following a traditional classroom environment simulation without students interacting with the application. Findings show a trend regarding the effect of the combined game elements mainly on the most autonomous forms of motivation in both countries.

\subsection{Points condition}

The students' experience with the prototype awarding points was effective in increasing intrinsic motivation. These results are consistent with the findings of Mekler et al. (2013), which showed the same effects regarding this game element. According to the authors, these effects may be due to their functioning as feedback: "Points establish a clear connection between user effort and performance. Moreover, people have an inherent need to accomplish tasks and providing them with individual performance information may facilitate the fulfilment of this need" (Mekler et al., 2013, p. 1140). Despite the positive effects under these specific conditions, research suggests that rewarding points, as an external stimulus, may undermine participants' 
interest in a task (Deci et al., 1999). Points can be awarded for a wide variety of settings - attending classes, solving problems, completing tasks - or can even be converted into tangible rewards, i.e. money or vouchers. In this ocean literacy prototype, points were rewarded every time the user threw the waste into the right bin. In a the previous study (Leitão et al., 2019b), students reported throwing waste into the right bin as a very funny and engaging interaction. This layer of fun combined with the natural user interface (touch) allowed by mobile platforms may have directed the effect of points towards increasing students' autonomy or self-determination level. Likewise, Csikszentmihalyi (2000) defined fun as a positive emotional state of playful enjoyment in which one is intrinsically engaged and, thus, valuing the experience by itself, rather than the experience as an instrument to achieve something else. Moreover, providing users with individual performance information could have also intensified the intrinsic motivation results. Moving in the opposite direction of autonomy or of self-determination, in this study the results turned to negative. This may be related to executing a task because of rewards or external coercive pressures, which may decrease this level of self-determination, though the game element points is a type of reward and external regulation. The outcomes of the application were to help students understand ocean literacy topics and, at the same time, connect our behaviours to the effects on the ocean. The points element was shown to have a higher positive effect regarding the identified regulation. According to these results, under the game element points the students valued the outcomes while interacting with this prototype, which suggests that in an educational context points could be used as a positive element to improve extrinsic motivation and the identified regulation layer.

\subsection{Badges condition}

Badges had a higher effect on intrinsic motivation, compared to the other layers, and this effect decreased while moving towards extrinsic motivational levels. Some studies reported an increase in student motivation, while others found that there was no impact or a negative impact on student motivation (Hakulinen \& Auvinen, 2014). Abramovich et al. (2013) found evidence that 'earning various badges can be associated with increases in expectations for success but also increases in counter-productive educational goals. Thus, in contrast to what might be expected from conceptualizing badges as only being extrinsic rewards (and therefore only bad for learning), we find evidence suggesting both positive and negative effects (Abramovich et al., 2013, p. 229).

As well as the game element points, badges are external rewards and can be awarded for a wide variety of settings (i.e. participation, skill acquisition, knowledge or achievement, progress). Different badge types can affect differently learners' motivation (Abramovich et al., 2013). Badges are visual awards and they are frequently offered to students as an incentive to engage in a behaviour in which they might not otherwise engage. According to Deci et al. (2001), this will tend to be experienced as controlling, and as a result, they will tend to decrease intrinsic motivation. Another factor that could influence their effect is using them as a social 
element (Consolvo et al., 2006; De-Marcos et al., 2014; Turner et al., 2014). Deterding (2011) suggests that using a gamified system that offers virtual rewards or public social comparison is not necessarily voluntary or free of consequence, two essential characteristics to increase intrinsic motivation according to the self-determination theory (Ryan \& Deci, 2000b). Social sharing (e.g. when learners can share their badges on social media) can have benefits of additional recognition from friends and family but can also cultivate social pressure over learners. Furthermore, social comparison leads to competition, which research suggests having negatives effects in the classroom (Reeve \& Deci, 1996). Following this, additional attention should be given at younger ages. However, social comparison can affect the motivational outcome in a different perspective. According to Schunk and Usher (2019): "Learners who observe others perform successfully may believe that they also can be successful. Students who observe successful models may believe that they can emulate their models' performances. Such a belief may raise their self-efficacy and lead them to engage in motivated behaviours". In the prototype, badges were used to display information about ocean topics (eutrophication, sea level rise and plastic pollution) and the aims of the game (quantity and quality of waste necessary to recycle). Every time the user reached one of the three badges, a window popped up congratulating the user, explaining a certain topic and relating it to our behaviour. Therefore, the badge was awarded based on positive feedback and as a personal achievement, consequently the higher results on intrinsic motivation may be due to the type of stimuli that was used. The findings are consistent with previous research, which reported the use of badges as a good motivational stimulus. For example, Hakulinen and Auvinen (2014) reported that after badges were introduced in the course, students' motivation increased in performance. Therefore, the results suggest that the game element badges, at least used in these conditions, seem to have a stronger effect on intrinsic motivation than on extrinsic motivation.

\subsection{Leaderboard condition}

Mixed results were found with respect to the impact of the leaderboard on students' motivation. Intrinsic motivation presented the highest increase of all the three game elements used individually, but at the same time amotivation (lack of intrinsic or extrinsic motivation) also displayed the highest increase in all the five conditions. Previous studies have shown different results regarding the impact of leaderboards on motivation. While some studies declared the leaderboard as a demotivating game element (De-Marcos et al., 2014; Werbach \& Hunter, 2012; Zichermann \& Cunningham, 2011), others presented good results regarding engagement, confidence and also good contribution to the learning process (Çakıroğlu et al., 2017; Domínguez et al., 2013; Hanus \& Fox, 2015; Nevin et al., 2014). The controversial results may be due to the different relationships that may occur between leaderboard and students, highlighted by Zuckerman and Gal-Oz (2014). Likewise, Lister (2015) noticed in an analysis of the literature, mixed results regarding the impact of leaderboards on student's motivation. The author suggested that, due to the immediate feedback it provides, the leaderboard can be very motivating for competitive 
students while less competitive students can demotivate and decrease their performance. The main reason presented for this game element to be effective as a source of intrinsic motivation is because students can see their work recognized by their peers immediately and because it can act as an inspiration for students to keep the performance for longer periods of time (Domínguez et al., 2013). By contrast, other research reported that leaderboards favoured competition over collaboration among students, reduced participation and could develop different motivation relationships for students (De-Marcos et al., 2014). Leaderboards naturally lead to competition and, as mentioned above, can diminish the overall performance, cooperation, problem solving and also develop negative effects in the classroom, therefore increasing amotivation. Similarly, Dijkstra et al. (2008) suggests that upward comparisons among students can evoke negative effects and lower academic self-concept (Dijkstra et al., 2008). Another reason for the negative results may be the students' difficulty to rise up the leaderboard because of the high scores of players above them, or even to get onto the leaderboard for new players. Therefore, one way to minimize this effect would be to show the player's name, position and the best score on the leaderboard along with the leaders.

External regulation refers to accomplishing an activity because of rewards or external coercive pressures. This least self-determined form of extrinsic motivation presented the highest increase of all sessions after the students' experience with the leaderboard. Since any pressure that could exist was minimized through an assurance that there were no wrong or right answers, these findings seem to show how important it was for the students to have a good position in the ranking. In fact, it was also possible to observe in the students' verbal and animated behaviour that they were much more active and more focused on their peers' results. These findings show that the game element leaderboard has the potential to create competition among the students and increase external regulation. In summary, this game element in an educational context may need some attention when used, since the results appear to show that it may have a different effect on students and increase amotivation among some of them.

\subsection{PBL triad condition}

Overall, the combination of points, badges and leaderboard (PBL triad) yielded the best results, compared to each game element alone. The students' interaction with this prototype was effective in increasing intrinsic motivation and decreasing amotivation. A possible explanation for this could be that the use of all the elements together enhanced the full gamified experience. As highlighted by previous authors (Chou, 2016; Deterding, 2013), a rich gamified experience cannot rely on merely adding game design elements, it is important to understand that games are powerful through the dynamic interaction of users with the whole system. Throughout the involvement in the process of failure and errors made, to the final success. Intrinsic motivation is strongly related to the interest and joy to learning and, therefore, the interaction of all elements together could have provided a better sense of fun, addressing a full experience of gameplay. Identified regulation also increased 
with the PBL triad, compared to the other sessions. As mentioned above, identified regulation refers to participating in an activity because its outcomes are valued. Thus, students considered the ocean literacy topics related to recycling as useful and important content for them. Furthermore, as well as in the case of the element badge, the results showed a decrease of the effect while going towards into extrinsic motivational levels. It seems that this combination of elements has a stronger effect on the most self-determined forms of extrinsic motivation. The positive effect observed could be due to the association between the application outcomes and students' learning experience. Also, when all game elements were combined the gamified system was probably not found to be controlling for the students and did not reduce the users' competence, relatedness and autonomy. It is important to note that these results may also be related to the fact that participation in the activity afforded sensations such as aesthetic experiences, sensory pleasure and fun of the full dynamic interaction with the system.

\subsection{Oral explanations only condition}

Intrinsic motivation results decreased and presented the lowest levels among all the sessions. Since intrinsic motivation involves the greatest degree of autonomous selfregulation, it could be that the students did not perceive this session as a pleasurable and autonomous activity. Another possible reason could be that the slideshow and the oral explanations about ocean literacy topics were insufficient to improve the level of competence with recycling or that the activity was not designed to be challenging enough for the students to increase their intrinsic motivation. Likewise, Deterding (2015) suggests challenge to be one of the principal stimuli to develop an engaging experience and thus to increase intrinsic motivation. External regulation, the least self-determined form of extrinsic motivation, also decreased after the students experienced this session. Since external regulation refers to accomplishing an activity because of rewards or external coercive pressures, the results suggest that students did not feel any incentive to pursue the activity because of the rewards. Lastly, amotivation results increased in this session, exposing an absence of students' intrinsic or extrinsic motivation. These results may be due to the fact that the students perceived no worthwhile reasons to participate in this activity. Furthermore, although the oral explanations stressed the amount of waste we produce and their consequence to the ocean, it is important to highlight that they weren't specifically about recycling, though they discussed the contribution of human actions to the severity of the ocean issues presented. Given the impact on amotivation, and the fact this is still the most used teaching method in schools, the results also reinforce the urgent need for introduction of more dynamic teaching methods in the classroom if we want to engage students in learning and protecting ocean health. Since points, badges and leaderboards are the most commonly employed game elements in education (Hamari et al., 2014; Seaborn \& Fels, 2015), these findings bring some insights regarding the motivation effects of different game elements to the research field and plan the development of other teaching gamification apps. 


\section{Limitations}

This study evaluated the effect of points, badges, leaderboard and the PBL triad on motivation to recycle among basic school students in two countries (Portugal and UK). The samples used in this study are not fully representative of the two countries from which they are drawn. Therefore, no significant association was found between objective game elements and the motivation to recycle. However, it was possible to identify some trends regarding their relationship. The literature shows that external motivators can work better in the short term rather than over long periods (Liu et al., 2017). The SIMS scale measures students' situational motivation while they are engaging in an activity, thus, future research should provide more information and deeper understanding regarding the effects of extrinsic rewards over time. As highlighted by Silpasuwanchai et al. (2016) "participating in the learning task for a short period does not mean that a learner is devoted" (Silpasuwanchai et al., 2016). The present study highlights the importance of the time perspective on learning motivation. Therefore, according to the different desired behaviours (short or long term), different game elements may be more appropriate to use. Moreover, motivation to recycle is a psychological outcome and not a behavioural outcome. Thus, a high motivation to recycle does not necessarily materializes into practice.

\section{Conclusions}

This study aimed to understand effects of different game elements on students' situational motivation to recycle. Results seems to point a trend concerning the effect of different game elements on motivation to recycle of students from both countries. All the sessions with the ocean literacy prototype application were shown to have the potential to improve the students' intrinsic motivation, but in different degrees of effectiveness. Therefore, gamified applications could help to stimulate students' intrinsic motivation by promoting the students' initiative to do the activity for itself, for the fun and the satisfaction that they experience while they learn. However, it is important to highlight that there is no one-size-fits-all model for the successful gamification of a learning activity.

The study found that the ocean literacy topic has the potential to trigger identified regulation among the students since this was the only motivation level that increased in all sessions. Considering this, these interactive technologies seem to have the potential to deliver more effective education for sustainable development than conventional teaching approaches. Since negative impacts on the ocean are a consequence of meeting our immediate human needs, the ocean literacy application increased students' motivation and also related our individual behaviours with a marine environmental issue. Lastly, the prototype version with the leaderboard as the main game element was shown to have a positive effect on intrinsic, extrinsic and amotivation levels of motivation, with a strong effect on intrinsic 
motivation and external regulation. The results suggest that this game element has a substantial effect on the least autonomous level (external regulation). In the recycling context this could represent only recycling in order to satisfy an external demand or to receive some reward.

Acknowledgements The authors are thankful to the student participants who took part of the study as well as the schools involved. We would also like to thank the Interdisciplinary Centre of Marine and Environmental Research (CIIMAR) for their help. This research was supported by the Arts and Humanities Research Council Design Star CDT (AH/L503770/1). The research was also supported by project OceanClass - Do oceano para a sala de aula funded by the Blue Growth Programme of EEA Grants Portugal (EEA.BG.SGS3.022.2019), (2021-2023) and by national funds through FCT (Foundation for the Science and Technology) within the scope of UIDB/04423/2020 and UIDP/04423/2020.

Open Access This article is licensed under a Creative Commons Attribution 4.0 International License, which permits use, sharing, adaptation, distribution and reproduction in any medium or format, as long as you give appropriate credit to the original author(s) and the source, provide a link to the Creative Commons licence, and indicate if changes were made. The images or other third party material in this article are included in the article's Creative Commons licence, unless indicated otherwise in a credit line to the material. If material is not included in the article's Creative Commons licence and your intended use is not permitted by statutory regulation or exceeds the permitted use, you will need to obtain permission directly from the copyright holder. To view a copy of this licence, visit http://creativecommons.org/licen ses/by/4.0/.

\section{References}

Abramovich, S., Schunn, C., \& Higashi, R. M. (2013). Are badges useful in education?: It depends upon the type of badge and expertise of learner. Educational Technology Research and Development, 61(2), 217-232. https://doi.org/10.1007/s11423-013-9289-2.

Ankamah-Yeboah, I., Xuan, B. B., Hynes, S., \& Armstrong, C. W. (2020). Public perceptions of DeepSea environment: Evidence from Scotland and Norway. Frontiers in Marine Science, 7. https://doi. org/10.3389/fmars.2020.00137.

Brophy, J. (2013). Motivating students to learn. Routledge. https://doi.org/10.4324/9780203858318.

Çakıroğlu, Ü., Başıbüyük, B., Güler, M., Atabay, M., \& Yılmaz Memiş, B. (2017). Gamifying an ICT course: Influences on engagement and academic performance. Computers in Human Behavior, 69, 98-107. https://doi.org/10.1016/j.chb.2016.12.018.

Cava, F., Schoedinger, S., Strang, C., \& Tuddenham, P. (2005). Science content and standards for ocean literacy: A report on ocean literacy. Retrieved June 3, 2021.

Chee, C.-M., \& Wong, D. H.-T. (2017). Affluent gaming experience could fail Gamification in education: A review. IETE Technical Review, 4602(July), 1-5. https://doi.org/10.1080/02564602.2017.13159 65.

Chou, Y.-K. (2016). Actionable gamification: Beyond points, badges, and leaderboards. Octalysis Media, 1-151. https://doi.org/10.1017/CBO9781107415324.004.

Consolvo, S., Everitt, K., Smith, I., \& Landay, J. A. (2006). Design requirements for technologies that encourage physical activity. In Proceedings of the SIGCHI conference on Human Factors in computing systems - CHI 'O6 (p. 457). ACM Press. https://doi.org/10.1145/1124772.1124840.

Costa, S., \& Caldeira, R. (2018). Bibliometric analysis of ocean literacy: An underrated term in the scientific literature. Marine Policy, 87, 149-157. https://doi.org/10.1016/j.marpol.2017.10.022.

Csikszentmihalyi, M. (1999). If we are so rich, why aren't we happy? American Psychologist, 54(10), 821-827. https://doi.org/10.1037/0003-066X.54.10.821.

Csikszentmihalyi, M. (2000). Beyond boredom and anxiety. Jossey-Bass.

Csikszentmihalyi, M. (2014). Toward a psychology of optimal experience. In Flow and the foundations of positive psychology (pp. 209-226). Springer Netherlands. https://doi.org/10.1007/978-94-0179088-8_14. 
Daigle, D. (2003). Involving the public in coastal conservation: Obstacles and opportunities. Values at Sea: Ethics for the Marine Environment, 230-238.

Deci, E. L., \& Ryan, R. M. (1985). Intrinsic motivation and self-determination in human behavior. Springer Science \& Business Media.

Deci, E., Ryan, R., \& Koestner, R. (1999). A meta-analytic review of experiments examining the effects of extrinsic rewards on intrinsic motivation. Psychological Bulletin, 125(6), 627-668. https://doi. org/10.1037/0033-2909.125.6.627.

Deci, E. L., Koestner, R., \& Ryan, R. M. (2001). Extrinsic rewards and intrinsic motivation in education : Reconsidered once again. Review of Educational Research, 71(1), 1-27.

De-Marcos, L., Domínguez, A., Saenz-De-Navarrete, J., \& Pagés, C. (2014). An empirical study comparing gamification and social networking on e-learning. Computers and Education, 75, 82-91. https:// doi.org/10.1016/j.compedu.2014.01.012.

Denny, P., McDonald, F., Empson, R., Kelly, P., \& Petersen, A. (2018). Empirical support for a causal relationship between Gamification and learning outcomes. In Proceedings of the 2018 CHI conference on human factors in computing systems - CHI '18 (pp. 1-13). ACM Press. https://doi.org/10. $1145 / 3173574.3173885$.

Deterding, S. (2011). Situated motivational affordances of game elements: A conceptual model. In Gamification: Using game design elements in non-gaming contexts, a workshop at CHI, vol. 10, no. 1979742.1979575.

Deterding, S. (2013). Skill atoms as design lenses for user-centered gameful design. In Workshop Papers CHI2013.

Deterding, S. (2015). The lens of intrinsic skill atoms: A method for gameful design. Human-Computer Interaction, 30(3-4), 294-335. https://doi.org/10.1080/07370024.2014.993471.

Dichev, C., \& Dicheva, D. (2017). Gamifying education: What is known, what is believed and what remains uncertain: A critical review. International Journal of Educational Technology in Higher Education, 14(1). https://doi.org/10.1186/s41239-017-0042-5.

Dicheva, D., Irwin, K., \& Dichev, C. (2018). Motivational Factors in Educational Gamification. In 2018 IEEE 18th International Conference on Advanced Learning Technologies (ICALT) (pp. 408-410). IEEE. https://doi.org/10.1109/ICALT.2018.00102.

Dicheva, D., Irwin, K., \& Dichev, C. (2019). Exploring learners experience of Gamified practicing: For learning or for fun? International Journal of Serious Games, 6(3), 5-21. https://doi.org/10.17083/ ijsg.v6i3.299.

Dijkstra, P., Kuyper, H., van der Werf, G., Buunk, A. P., \& van der Zee, Y. G. (2008). Social comparison in the classroom: A review. Review of Educational Research, 78(4), 828-879. https://doi.org/10. 3102/0034654308321210.

Domínguez, A., Saenz-De-Navarrete, J., De-Marcos, L., Fernández-Sanz, L., Pagés, C., \& Martínez-Herráiz, J.-J. (2013). Gamifying learning experiences: Practical implications and outcomes. Computers and Education, 63, 380-392. https://doi.org/10.1016/j.compedu.2012.12.020.

EEA, E. E. A. (2019). Europe's seas and coasts. Retrieved February 2, 2020, from https://www.eea. europa.eu/themes/water/europes-seas-and-coasts/europes-seas-and-coasts.

Esteves, J. M. (2017). The perils of gamification triviliazation: How and why gamification is failing to deliver loyalty. Academy of Management Proceedings, 2017(1), 13560. https://doi.org/10.5465/ AMBPP.2017.13560abstract.

Falasca-Zamponi, S. (2010). Waste and Consumption. Waste and Consumption. Routledge. https://doi. org/10.4324/9780203834275.

Fauville, G., Strang, C., Cannady, M. A., \& Chen, Y.-F. (2019). Development of the International Ocean literacy survey: Measuring knowledge across the world. Environmental Education Research, 25(2), 238-263. https://doi.org/10.1080/13504622.2018.1440381.

Frick, J., Kaiser, F. G., \& Wilson, M. (2004). Environmental knowledge and conservation behavior: Exploring prevalence and structure in a representative sample. Personality and Individual Differences, 37(8), 1597-1613. https://doi.org/10.1016/j.paid.2004.02.015.

Goodale, T. A. (2020). Factors That Influence Curricular Adoption in a Sustainability Focused Marine Science Professional Development for In-Service Teachers. Journal of Education for Sustainable Development, 097340822093464. https://doi.org/10.1177/0973408220934645.

Guay, F., Vallerand, R. J., \& Blanchard, C. (2000). On the assessment of situational motivation scale. Motivation and Emotion, 24(3), 175-213.

Guest, H., Lotze, H. K., \& Wallace, D. (2015). Youth and the sea: Ocean literacy in Nova Scotia, Canada. Marine Policy, 58, 98-107. https://doi.org/10.1016/j.marpol.2015.04.007. 
Hakulinen, L., \& Auvinen, T. (2014). The effect of gamification on students with different achievement goal orientations. In Teaching and Learning in Computing and Engineering (LATICE), 2014 International Conference (pp. 9-16). https://doi.org/10.1109/LaTiCE.2014.10

Hamari, J., Koivisto, J., \& Sarsa, H. (2014). Does gamification work? - A literature review of empirical studies on gamification. Proceedings of the Annual Hawaii International Conference on System Sciences, 3025-3034. https://doi.org/10.1109/HICSS.2014.377.

Hanus, M. D., \& Fox, J. (2015). Assessing the effects of gamification in the classroom: A longitudinal study on intrinsic motivation, social comparison, satisfaction, effort, and academic performance. Computers and Education, 80, 152-161. https://doi.org/10.1016/j.compedu.2014.08.019.

Hense, J., \& Mandl, H. (2014). Learning in or with games? Quality criteria for digital learning games from the perspectives of learning, emotion, and motivation theory. Springer International Publishing.

Ibáñez, M.-B., \& Delgado-kloos, C. (2014). Gamification for engaging computer science students in learning activities : A case study. Transactions on Learning Technologies, 7(3), 291-301.

Kapp, K. M. (2012). The gamification of learning and instruction: Game-based methods and strategies for training and education. Wiley.

Kirillov, A. V., Melnichuk, A. V., Bondaletov, V. V., Li, N. P., \& Lvova, M. A. (2018). Gamification for the motivation of scientific and pedagogical staff. Turkish Online Journal of Design, Art and Communication, 8(SEPT), 1044-1056. https://doi.org/10.7456/1080SSE/144.

Kornevs, M., Baalsrud Hauge, J., \& Meijer, S. (2019). Gamification of a procurement process for professional training of public servants. International Journal of Serious Games, 6(2), 23-37. https://doi. org/10.17083/ijsg.v6i2.293.

Landers, R. N., Bauer, K. N., \& Callan, R. C. (2017). Gamification of task performance with leaderboards: A goal setting experiment. Computers in Human Behavior, 71, 508-515. https://doi.org/ 10.1016/j.chb.2015.08.008.

Lawlor, J., Marshall, K., \& Tangney, B. (2016). Bridge21 - exploring the potential to foster intrinsic student motivation through a team based, technology-mediated learning model. Technology, Pedagogy and Education, 25(2), 187-206. https://doi.org/10.1080/1475939X.2015.1023828.

Leitão, R., Maguire, M., Turner, S., Guimarães, L., \& Arenas, F. (2018). Ocean literacy and information sources: comparison between pupils in Portugal and the UK. $12^{\text {th }}$ Annual International Technology, Education and Development Conference, March, 5058-5067. https://doi.org/10. 21125/inted.2018.0998

Leitão, R., Maguire, M., \& Turner, S. (2019a). Ocean literacy app (6.5). https://play.google.com/store/ apps/details?id=org.rvleitao.oceanliteracy

Leitão, R., Maguire, M., \& Turner, S. (2019b). Students' participation in the design process: a study on user experience of an educational game-like application. $11^{\text {th }}$ Annual International Conference on Education and New Learning Technologies, 5381-5390. https://doi.org/10.21125/edule arn.2019.1322

Leitão, R., Turner, S., \& Maguire, M. (2019c). Gamification and education: a study of the effects on students situational motivation. $11^{\text {th }}$ Annual International Conference on Education and New Learning Technologiesc, 3110-3118. https://doi.org/10.21125/edulearn.2019.0841

Lister, M. (2015). Gamification: The effect on student motivation and performance at the post-secondary level. Issues and Trends in Educational Technology, 3(2). https://www.learntechlib.org/p/ $171075 /$

Liu, D., Santhanam, R., Webster, J., Liu, D., Santhanam, R., \& Webster, J. (2017). Toward meaningful engagement: A framework for design and research of Gamified information systems. MIS Quarterly, 41(4), 1011-1034.

Lonsdale, C., Sabiston, C. M., Taylor, I. M., \& Ntoumanis, N. (2011). Measuring student motivation for physical education: Examining the psychometric properties of the perceived locus of causality questionnaire and the situational motivation scale. Psychology of Sport and Exercise, 12(3), 284-292. https://doi.org/10.1016/j.psychsport.2010.11.003.

Loughrey, K., \& O Broin, D. (2018). Are We Having Fun Yet? Misapplying Motivation to Gamification. In 2018 IEEE Games, Entertainment, Media Conference (GEM) (pp. 1-9). IEEE. https:// doi.org/10.1109/GEM.2018.8516535.

Magni, M., Susan Taylor, M., \& Venkatesh, V. (2010). 'To play or not to play': A cross-temporal investigation using hedonic and instrumental perspectives to explain user intentions to explore a technology. International Journal of Human-Computer Studies, 68(9), 572-588. https://doi.org/ 10.1016/j.ijhcs.2010.03.004. 
Marrero, M. E., \& Mensah, F. M. M. (2010). Socioscientific decision making and the ocean: A case study of 7 th grade life science students. The Electronic Journal for Research in Science \& Mathematics Education, 1(14).

Mekler, E. D., Brühlmann, F., Opwis, K., \& Tuch, A. N. (2013). Disassembling gamification: The effects of points and meaning on user motivation and performance. In CHI ' 13 extended abstracts on human factors in computing systems on - CHI EA '13 (pp. 1137-1142). ACM Press. https://doi.org/10.1145/2468356.2468559.

Mercer, T. G., Kythreotis, A. P., Robinson, Z. P., Stolte, T., George, S. M., \& Haywood, S. K. (2017). The use of educational game design and play in higher education to influence sustainable behaviour. International Journal of Sustainability in Higher Education, 18(3), 359-384. https://doi. org/10.1108/IJSHE-03-2015-0064.

Nevin, C. R., Westfall, A. O., Rodriguez, J. M., Dempsey, D. M., Cherrington, A., Roy, B., et al. (2014). Gamification as a tool for enhancing graduate medical education. Postgraduate Medical Journal, 90(1070), 685-693. https://doi.org/10.1136/postgradmedj-2013-132486.

Østerlie, O., Løhre, A., Haugan, G., \& Hui, S. K. F. (2019). The situational motivational scale (SIMS) in physical education: A validation study among Norwegian adolescents. Cogent Education, 6(1). https://doi.org/10.1080/2331186X.2019.1603613.

Pantò, E. (2019). A game for Learning Ocean literacy: The ResponSEAble project. International Information \& Library Review, 51(3), 247-252. https://doi.org/10.1080/10572317.2019.16290 67.

Papathanassiou, M., McHugh, P., Domegan, C., Gotensparre, S., Fauville, G., \& Parr, J. (2017). Barriers to teaching ocean science in Greek schools. In EGU General Assembly Conference Abstracts (p. 13965).

Park, J., Liu, D., Yi, M. Y., \& Santhanam, R. (2019). GAMESIT: A gamified system for information technology training. Computers \& Education, 142, 103643. https://doi.org/10.1016/j.compedu.2019. 103643.

Przybylski, A. K., Rigby, C. S., \& Ryan, R. M. (2010). A motivational model of video game engagement. Review of General Psychology, 14(2), 154-166. https://doi.org/10.1037/a0019440.

Rapp, A., Hopfgartner, F., Hamari, J., Linehan, C., \& Cena, F. (2019). Strengthening gamification studies: Current trends and future opportunities of gamification research. International Journal of Human-Computer Studies, 127, 1-6. https://doi.org/10.1016/j.ijhcs.2018.11.007.

Reeve, J., \& Deci, E. L. (1996). Elements of the competitive situation that affect intrinsic motivation. Personality and Social Psychology Bulletin, 22(1), 24-33. https://doi.org/10.1177/0146167296221003.

Rigby, C. S. (2015). Gamification and motivation. In The Gameful World (pp. 113-138). The MIT press. https://doi.org/10.7551/mitpress/9788.003.0008.

Ryan, R., \& Deci, E. (2000a). Intrinsic and extrinsic motivations: Classic definitions and new directions. Contemporary Educational Psychology, 25(1), 54-67. https://doi.org/10.1006/ceps.1999.1020.

Ryan, R. M., \& Deci, E. L. (2000b). Self-determination theory and the facilitation of intrinsic motivation. American Psychologist, 55(1), 68-78. https://doi.org/10.1037/0003-066X.55.1.68.

Ryan, R. M., Rigby, C. S., \& Przybylski, A. (2006). The motivational pull of video games: A selfdetermination theory approach. Motivation and Emotion, 30(4), 344-360. https://doi.org/10.1007/ s11031-006-9051-8.

Sailer, M., Hense, J. U., Mayr, S. K., \& Mandl, H. (2017). How gamification motivates: An experimental study of the effects of specific game design elements on psychological need satisfaction. Computers in Human Behavior, 69, 371-380. https://doi.org/10.1016/j.chb.2016.12.033.

Schunk, D. H., \& Usher, E. L. (2019). Social cognitive theory and motivation. In R. M. Ryan (Ed.), The Oxford Handbook of Human Motivation (pp. 9-26). Oxford University Press. https://doi.org/10. 1093/oxfordhb/9780190666453.013.2.

Seaborn, K., \& Fels, D. I. (2015). Gamification in theory and action: A survey. International Journal of Human Computer Studies, 74, 14-31. https://doi.org/10.1016/j.ijhcs.2014.09.006.

Silpasuwanchai, C., Ma, X., Shigemasu, H., \& Ren, X. (2016). Developing a comprehensive engagement framework of Gamification for reflective learning. In Proceedings of the 2016 ACM conference on designing interactive systems - DIS '16 (pp. 459-472). ACM Press. https://doi.org/10.1145/29017 90.2901836 .

Standage, M., Duda, J. L., Treasure, D. C., \& Prusak, K. A. (2003). Validity, reliability, and invariance of the situational motivation scale (SIMS) across diverse physical activity contexts. Journal of Sport and Exercise Psychology, 25(1), 19-43. https://doi.org/10.1123/jsep.25.1.19. 
Thiebes, S., Lins, S., \& Basten, D. (2014). Gamifying information systems - a synthesis of gamification mechanics and dynamics. In Twenty Second European Conference on Information Systems (pp. 0-17). Tel Aviv. Retrieved from http://aisel.aisnet.org/ecis2014/ http://aisel.aisnet.org/ecis2014/ proceedings/track01/4

Tran, L. U. (2009). Children and adults' understanding of ocean and climate sciences. In Committee for the Review of the NOAA Education Program (pp. 1-53).

Turner, C., Dierksheide, J., \& Anderson, P. (2014). Learn2Mine: Data Science Practice and Education through Gameful Experiences. International Journal of E-Education, e-Business, e-Management and e-Learning, 4(3). https://doi.org/10.7763/IJEEEE.2014.V4.338.

Werbach, K. (2014). ( Re ) Defining Gamification : A Process Approach. In Persuasive Technology (Vol. 8462, pp. 266-272). Springer International Publishing. https://doi.org/10.1007/978-3-319-07127-5_ 23.

Werbach, K., \& Hunter, D. (2012). For the win: How game thinking can revolutionize your business. Wharton Digital Press.

Williams, K. C., \& Williams, C. C. (2011). Five key ingredients for improving student motivation. Research in Higher Education Journal, 12, 1-23 Retrieved from http://www.jupapadoc.startlogic. com/manuscripts/11834.pdf.

Winks, L., Ward, M., Zilch, J., \& Woodley, E. (2020). Residential marine field-course impacts on ocean literacy. Environmental Education Research, 1-20. https://doi.org/10.1080/13504622.2020.17586 31.

Xu, Y. (2011). Literature Review on Web Application Gamification and Analytics. Honolulu, HI, (August). Retrieved from http://csdl-techreports.googlecode.com/svn-history/r674/trunk/techr eports/11-05/11-05.pdf.

Zichermann, G., \& Cunningham, C. (2011). Gamification by Design: Implementing Game Mechanics in Web and Mobile Apps. O'Reilly Media.

Zuckerman, O., \& Gal-Oz, A. (2014). Deconstructing gamification: Evaluating the effectiveness of continuous measurement, virtual rewards, and social comparison for promoting physical activity. Personal and Ubiquitous Computing, 18(7), 1705-1719. https://doi.org/10.1007/s00779-014-0783-2.

Publisher's note Springer Nature remains neutral with regard to jurisdictional claims in published maps and institutional affiliations.

\section{Authors and Affiliations}

\section{Rui Leitão ${ }^{1,2}$ (D) Martin Maguire ${ }^{1} \cdot$ Sarah Turner $^{3} \cdot$ Laura Guimarães $^{2}$}

Martin Maguire

m.c.maguire@lboro.ac.uk

Sarah Turner

s.turner4@lboro.ac.uk

Laura Guimarães

lcoutinho@ciimar.up.pt

1 School of Design and Creative Arts, Loughborough University, Epinal Way, Loughborough, Leicestershire LE11 3TU, UK

2 Interdisciplinary Centre of Marine and Environmental Research (CIIMAR), University of Porto, Porto, Portugal

3 Centre for Academic Practice, Loughborough University, Epinal Way, Loughborough, Leicestershire LE11 3TU, UK 